\title{
ANÁLISE DA DECISÃO DE RECEBIMENTO DA DENÚNCIA DE INCITAÇÃO AO CRIME DE ESTUPRO - INQUÉRITO 3.932/DF - COM BASE NA TEORIA ARGUMENTATIVA DE NEIL MACCORMICK
}

Daniel Camurça Correia ${ }^{1}$

Ana Cristina Viana Loureiro Gonçalves ${ }^{2}$

Luzélia Falcão Rocha Lima ${ }^{3}$

\section{Resumo}

Este trabalho analisa o recebimento da denúncia (Inquérito 3.932/DF) ofertada pelo Ministério Público Federal em desfavor do Deputado Federal Jair Bolsonaro (PSC-RJ), pela suposta prática do crime de incitação ao crime, ao declarar que a Deputada Federal Maria do Rosário (PT-RS) "não merece ser estuprada por ser muito ruim, muito feia, não faz meu gênero", acrescentando que, se ele fosse estuprador, "não iria estuprá-la porque ela não merece". O tema teve grande repercussão no contexto social brasileiro. A despeito do clamor social, o tema é complexo do ponto de vista jurídico, tendo em vista tocar à imunidade parlamentar, por um lado, e à dignidade sexual da mulher, por outro, o que denota a importância do debate jurídico. Busca-se, por isso, saber se o recebimento da denúncia, no caso, se apresenta corretamente fundamentado, do ponto de vista jurídico. Utiliza-se o método dedutivo para categorizar, com base numa análise descritivo-analítica da teoria da argumentação jurídica de Neil MacCormick, os argumentos utilizados como fundamentos da decisão e avaliar se essa decisão expressa argumentos coerentes e consistentes, de modo a aferir a correção ou não de sua fundamentação. Como resultado, conclui-se que a decisão de recebimento da denúncia por incitação ao crime de estupro, no caso apresentado, é adequadamente fundamentada, por utilizar-se de argumentos interpretativos tanto de ordem jurídica como prática, que guardam coerência narrativa e normativa e consistência argumentativa.

Palavras-chave: Argumentação jurídica; Coerência; Consistência.

\section{INTRODUÇÃO}

Em julgado ocorrido em 21 de junho de 2016, o Supremo Tribunal Federal recebeu denúncia e queixacrime (Inquérito 3.932/DF) em desfavor do Deputado Federal Jair Bolsonaro (PSC-RJ), pela suposta prática dos

\footnotetext{
${ }^{1}$ Pós-doutorando pelo Programa de Pós-graduação em Direito Constitucional da Universidade de Fortaleza. Professor das disciplinas de Ciência Política e Filosofia do Direito da UNIFOR. Líder do Grupo de Pesquisa em Filosofia do Direito (2013CNPQ/UNIFOR). Avaliador nacional e internacional do Conselho Nacional de Pesquisa e Pós-graduação em Direito-COPEDI. E-mail: danielcamurcac@yahoo.com.br

${ }^{2}$ Mestre em Direito Constitucional pela Universidade de Fortaleza. E-mail: cristinaviana1505@gmail.com

${ }^{3}$ Mestre em Direito Constitucional da Universidade de Fortaleza. E-mail: luzeliafalcao@hotmail.com
} 
crimes de incitação ao crime e injúria, arts. 286 e 140 do Código Penal, respectivamente.

O Denunciado afirmou, durante uma discussão no plenário da Câmara, que a Deputada Federal Maria do Rosário (PT-RS), "não merece ser estuprada”. No dia seguinte, em entrevista concedida em seu gabinete ao jornal "Zero Hora", reiterou as declarações, dizendo que a Deputada Federal Maria do Rosário "não merece ser estuprada por ser muito ruim, muito feia, não faz meu gênero", acrescentando que, se ele fosse estuprador, "não iria estuprá-la porque ela não merece".

A denúncia ofertada pelo Procurador-Geral da República afirma que o Denunciado, com sua conduta, estaria inflamando o crime de estupro, incorrendo, portanto, no delito do art. 286 do CPB. A vítima, também em razão dos fatos narrados, ajuizou queixa-crime alegando ter sido vítima de injúria, Art. 140 do CPB.

O fato teve grande repercussão nacional, movimentando, principalmente, a imprensa e redes sociais, com especial atenção para a incitação ao crime de estupro. Por um lado, comentários de apoio às afirmações assacadas pelo Denunciado demonstravam a percepção social de que o estupro é visto, por parte da população, como um crime no qual a vítima (mulher) concorre para o seu acontecimento, quer por seu comportamento moral, quer por seu vestuário ou mesmo pela beleza da vítima. Por outro, foram inciadas campanhas combatendo discursos denotativos de violência sexual contra mulher e sua vitimização, tais como a campanha \#EuNãoMereçoSerEstuprada e \#EstuproNãoÉCulpaDaVítima.

Além disso, o fato do Denunciado ser Deputado Federal, também suscitou o debate acerca da responsabilidade criminal, ante a imunidade parlamentar absoluta, pois as primeiras declarações foram prestadas em tribuna e a reiteração dessas ocorreu no âmbito do gabinete parlamentar.

A tese da defesa, além da imunidade parlamentar absoluta, que assegura ao exercente dessa atividade a proteção de sua liberdade de expressão, sustentou a atipicidade da conduta alegando que não houve incitação à prática do crime de estupro e que afirmações genéricas não são suficientes para o preenchimento das elementares do tipo penal.

Assim, embora se tratando de juízo superficial, o recebimento da denúncia teve que passar por temas tortuosos e relevantes para o contexto social brasileiro. O Supremo Tribunal Federal expediu sua decisão apresentando argumentos de diversas ordens. Desde os tratados e convenções internacionais de proteção da mulher contra a violência e discriminação às consequências que o não recebimento da denúncia causaria à ordem social.

Explique-se que a análise da decisão se restringe tão somente aos aspectos jurídicos relacionados com o recebimento da denúncia, vez que o crime de injúria, embora alusivo, também, com a condição de mulher da vítima, tem caráter subjetivo. Interessa assim o recorte quanto a conduta que, direta ou indiretamente, pode 
ensejar a intensificação da violência de gênero como um todo, tendo em vista que essa se opõe de forma mais veemente aos princípios e valores que fundamentam o Estado Democrático de Direito (igualdade e dignidade).

Diante do inegável clamor social que envolve o tema, difícil é a tarefa de analisar o assunto sob o ponto de vista jurídico. Para uma avaliação jurídica do recebimento da denúncia por incitação ao crime de estupro, no caso, importa questionar se essa decisão apresenta-se corretamente fundamentada. Eis o problema que se busca enfrentar.

Sem realizar qualquer juízo de mérito definitivo sobre a responsabilidade criminal do Denunciado quanto aos fatos narrados, a análise da decisão será realizada com base no voto do Relator do acórdão, à luz da teoria de Neil MacCormick, identificando-se os argumentos linguísticos, sistêmicos e teleológicos-deontológicos utilizados, para aferir se eles se apresentam coerentes e consistentes.

Para alcançar o objetivo proposto, a análise será realizada com base no método dedutivo. É dizer, o referencial teórico do que seja uma decisão corretamente fundamentada será o que assim é considerado pela teoria da argumentação jurídica de Neil MacCormick.

A metodologia é descritivo-analítica, na medida em que para atingir ao objetivo traçado, faz-se um panorama da teoria da argumentação jurídica de Neil MacCormick, com ênfase na categorização dos argumentos interpretativos eleitos por MacCormick como necessários para avaliar se uma decisão judicial está corretamente fundamentada, e na utilização da coerência e da consistência como complementos para aferir a correção ou não da fundamentação da decisão judicial.

O desenvolvimento do artigo se divide em quatro seções. Na primeira seção traça-se um panorama da teoria da argumentação jurídica de Neil MacCormick. Em seguida, são apresentados os argumentos interpretativos considerados necessários para aferir se uma decisão está corretamente fundamentada. A terceira seção do desenvolvimento expressa a ideia de MacCormick sobre a coerência e a consistência serem complementos à análise da fundamentação adequada da decisão judicial. Com essa explanação teórica, na quarta seção, serão analisados os argumentos apresentados no acórdão lavrado em decorrência do recebimento da denúncia de incitação ao crime de estupro, identificando-se se há a presença de argumentos linguísticos, sistêmicos e teleológicos-deontológicos, e se estes se encontram coerentes e consistentes, de modo que se possa associar a argumentação jurídica e a argumentação prática para, com isso, na conclusão, afirmar se, juridicamente, a decisão é correta ou não. 


\section{PANORAMA DA TEORIA DA ARGUMENTAÇÃO JURÍDICA DE NEIL MACCORMICK}

Neil MacCormick (1941-2009) é considerado um dos juristas mais importantes do século XX, sendo conhecido, também, como "o maior intelectual do Partido Nacional Escocês". Principal redator do "Projeto de Constituição para uma Escócia Independente" (oficialmente lançado em 2002), membro do Parlamento Europeu (1999-2004) e membro suplente da Convenção sobre o Futuro da Europa (2002-2003). Suas obras contribuem para o debate de temas como raciocínio jurídico, a relação entre lei e poder, o liberalismo e o nacionalismo e teoria constitucional no Reino Unido e na Europa (DEL MAR).

Dentre as importantes contribuições de sua obra, o autor buscou sistematizar uma teoria da argumentação jurídica, visando demonstrar como avaliar se uma decisão está corretamente fundamentada e apresentar um roteiro para que se produza uma boa decisão. A obra "Argumentação jurídica e teoria do direito", cuja versão original, inglesa, foi lançada em 1978, é o primeiro trabalho sistematizado do autor para formular uma teoria da argumentação jurídica. Além de expor de forma detalhada teoria, o autor realiza uma defesa do positivismo (MARTINS; ROESLER; JESUS, 2011, p. 209).

O positivismo defendido por MacCormick, com base nas ideias de Hart ${ }^{4}$, atribui considerável importância aos princípios gerais na argumentação jurídica. Posteriormente, o autor se afasta do pensamento de Hart, reconhecendo que a teoria do reconhecimento não é satisfatória para explicar a unidade do sistema jurídico, diante da complexidade do atual Estado constitucional, além de não ser possível olvidar as conexões entre direito, política e economia, e, ainda, a influência recíproca entre o direito e a moral. Em "Retórica e Estado de Direito" (2008), o autor declara-se como pós-positivista, embora não esclareça o sentido de tal definição5 (MARTINS; ROESLER; JESUS, 2011, p. 210).

\footnotetext{
${ }^{4}$ Hart propôs-se a "aprofundar a compreensão do direito, da coerção e da moral como fenómenos sociais diferentes mas relacionados" (sic). Para responder à pergunta "O que é Direito?”, sem pretender oferecer um conceito estático, mas de criar uma teoria geral do Direito, Hart trabalhou três questões: "como diferem o direito e a obrigação jurídica das ordens baseadas em ameaças e como se relacionam com estas?”; como diferem a obrigação jurídica da obrigação moral e como se relacionam? O que são regras e é o Direito apenas uma questão de regras? Assim, no decurso de seu trabalho, Hart descreveu quais os tipos de normas existentes nos Estados de Direito Moderno, as formas de reconhecimento das normas jurídicas, e as formas de alteração e de imposição dessas, buscando construir uma teoria que oferecesse um relato explicativo e clarificador do Direito como instituto social e político complexo (HART, H.L.A. O conceito de Direito. Tradução: A. Ribeiro Mendes. 3a ed. Lisboa: Fundação Calouste Gulbenkian.)

${ }^{5}$ Para compreender a consequência dessa autoafirmação para o pensamento de MacCormick, importa destacar que o póspositivismo reconhece a problemática da indeterminação do Direito e da insuficiência de suas fontes para resolver casos dificeis. Muitas constituições modernas existem princípios morais incorporados como direitos fundamentais, por isso admitem, também, a conexão entre direito e moral. Com isso, há uma mudança na forma como é pensada a relação entre direito, moral e política, a partir do reconhecimento da centralidade dos princípios jurídicos como fundamento de solução dos casos difíceis (MARTINS; ROESLER; JESUS, 2011, p. 211).
} 
De toda forma, MacCormick permanece íntegro na defesa da racionalidade do processo decisório no direito. Para ele, o argumento deverá ser racionalmente defensável, sendo a palavra instrumento de persuasão racional e a coerção decorrente apenas da força irrefutável de um argumento (MARTINS; ROESLER; JESUS, 2011, p. 212).

Para MacCormick, a argumentação jurídica está associada à argumentação prática, é dizer, o ser humano aplica a razão para decidir qual a forma correta de se comportar em situações que permitem escolha. Com esse fundamento, admite que o direito pode se servir da lógica e do raciocínio dedutivo para justificar as decisões. A despeito de não ser exclusivamente silogística, a argumentação jurídica não pode prescindir do raciocínio dedutivo, pois ele corresponde a uma parte do âmbito formal de correção de uma decisão que estabelece limites formais - dentro dos quais o juiz tem o dever de decidir (MARTINS; ROESLER; JESUS, 2011, p. 213).

A justificação das decisões constitui, no Estado Democrático do Direito, condição de sua legitimidade, na medida em que evidencia sua submissão aos preceitos constitucionais democráticos, possibilitando àqueles em nome de quem o poder é exercido aferirem se a opção escolhida pela autoridade foi a melhor. É para esse fim que MacCormick apresenta uma teoria argumentativa (LOPES; BENÍCIO, 2015, p. 40).

\section{OS ARGUMENTOS INTERPRETATIVOS}

Os argumentos devem ser estabelecidos para fundamentar a interpretação particular de uma razão autoritativa implantada como base para uma decisão. Com isso, tanto a interpretação é relevante para o argumento, como a argumentação também é importante para a interpretação:

(...) Os argumentos podem ser, e deveriam ser, implantados para mostrar razões a favor da interpretação preferida, num cenário em que nosso julgamento interpretativo é uma condição necessária da pertinente aplicabilidade de uma razão autorizativa para tomar a decisão. Desta forma, a interpretação não é apenas relevante para o argumento, mas também o argumento é importante para a interpretação. Entre os argumentos relevantes para a decisão, estão aqueles que apoiam ou se opõem a uma certa interpretação de uma razão autorizativa, utilizada como fundamento de uma (possível) decisão ${ }^{6}$ (MACCORMICK, 2010, p. 69) (tradução nossa).

Para MacCormick (2006, p. 18), justificar significa demonstrar que as decisões estão de acordo com o direito. Na prática, os argumentos têm como objetivo persuadir, mas, ao lado desse objetivo prático, têm a função de justificação. Ao tomar uma decisão, o julgador deve, à luz da conclusão sob o caso concreto, expor o raciocínio

\footnotetext{
6"(...) Los argumentos pueden ser, y tendrín que ser, desplegados para mostrar razones a favor de la interpretación preferida, em un escenario em el cual nuestro juicio interpretativo es una condición necesaria de la aplicabilidad relevante de una razón autoritativa para tomar la decisión. De esse modo la interpretación no sólo es relevante para la argumentación, son que también la argumentación es importante para la interpretación. Entre los argumentos relevantes para la decisión están aquellos que respaldan o se oponen a una determinada interpretación de una razón autoritativa desplegada como fundamento de una (posible) decisión" (MACCORMICK, 2010, p. 69).
} 
utilizado, demonstrando porque a ordem judicial é justificada à luz dos fatos, das normas jurídicas pertinentes e outras considerações que levaram àquela decisão.

O objetivo da teoria de MacCormick não é avaliar o mérito da decisão mas a adequação do raciocínio que a justifica. Seu valor se revela especialmente quando se trata de decisões judiciais que demandam do julgador construir uma solução com base no sistema jurídico como um todo, ante a ausência de resposta em lei específica (LOPES; BENÍCIO, 2015, p. 41).

Tal ocorre em situações em que não há uma lei clara da qual se deduza a decisão ou mesmo um precedente específico vinculativo, os chamados hard cases, nos quais, como foi dito, as soluções precisam ser construídas, exigindo-se um ato de interpretação.

O modelo apresentado por MacCormick confere destaque a três categorias de argumentos interpretativos: 1) argumentos linguísticos; 2) argumentos sistêmicos e 3) argumentos teleológicos/deontológicos.

\section{Argumentos linguísticos}

Os argumentos linguísticos são divididos em duas classes: a) significado ordinário do texto; e b) significado técnico. Se uma disposição legislativa tem significado óbvio e inteligível, o texto jurídico assume o mesmo uso comum, coloquial, isto é, em si, uma boa razão para dar o efeito para o significado de "ordinário". Por outro lado, se o texto se vale um vocabulário especializado, os termos que possuem um significado técnico e significado ordinário melhor são compreendidos no seu sentido técnico (MACCORMICK, 2010, p. 70).

$\mathrm{Na}$ tarefa interpretativa, cabe ao julgador desvelar o sentido do texto, sendo-lhe aplicável a mesma recomendação direcionada ao legislador, de que a linguagem utilizada seja clara, inteligível, de modo a gerar confiança nos cidadãos dos termos e significados comuns expressados, para uma comunicação efetiva e livre de problemas, minimizando os inconvenientes e os litígios sobre a interpretação adequada com os cidadãos (MACCORMICK, 2010, p. 71).

\section{Argumentos sistêmicos}

Como os sistemas jurídicos incluem uma multiplicidade de regras de interação de diferentes tipos, que expressam uma pluralidade de princípios e opções políticas, os argumentos interpretativos apontados são capazes de conferir, na maior medida possível, significado às normas conjuntamente e tomadas como um todo. A prática de interpretar a lei de maneira consistente tanto na forma e no conteúdo é o que possibilita manter a integridade do sistema jurídico, daí a relevância dos argumentos sistêmicos. 
Argumentos sistêmicos são aqueles que orientam para uma compreensão aceitável de um texto jurídico, visto como parte de um sistema jurídico. São classificados como argumentos de harmonização contextual, de precedente, de analogia, lógico-conceituais, de princípios gerais do Direito e históricos (MACCORMICK, 2010, p. 71).

O peso desses argumentos no sistema jurídico se relaciona com o fato de que nenhuma comunicação é plenamente compreensível se não se considerar o contexto completo de sua emissão. Todas as matérias legais são expressas no contexto do sistema jurídico em geral, à luz de um complexo de circunstâncias legais, políticas e históricas (MACCORMICK, 2010, p. 73).

\section{Argumento de harmonização contextual}

Uma disposição jurídica deve ser interpretada à luz do regime a que pertence, ou seja, levando em consideração a lei ou conjunto de leis em que está inserida. De uma forma mais específica, deve ser interpretado à luz das disposições da lei que tem o relacionamento mais próximo ou de outra lei que trate de matéria de mais semelhante, e o significado "ordinário" ou "técnico" mais ou menos óbvio deve ser interpretado sob esse enfoque (MACCORMICK, 2010, p. 72).

\section{Argumento de precedente}

Deve-se aplicar a mesma interpretação judicial prevalente que já foi dada a uma disposição anterior, é dizer, conforme o entendimento já lançado por outros tribunais, de maior hierarquia ou, não sendo o caso, que se verifique de forma reiterada (MACCORMICK, 2010, p. 72).

\section{$\underline{\text { Argumentos de analogia }}$}

Havendo dispositivo legal análogo a outras disposições em outra lei, ou em um código ou em outra parte do mesmo código em que aparece, a interpretação mais adequada seria a que assegurasse a similaridade do sentido com o dispositivo análogo, mesmo que isso importasse no abandono do significado comum. A interpretação por analogia pode ser da norma em si mesma ou derivada de interpretação judicial prévia, caso que incorpora uma versão do argumento do precedente (MACCORMICK, 2010, p. 72).

\section{Argumento lógico-conceitual}

Uma vez utilizado um conceito jurídico geral, reconhecido e produzido pela doutrina, na formulação de 
um dispositivo legislativo, a interpretação deve manter o uso consistente do mesmo, através do sistema como um todo, ou de algum ou alguns dos seus ramos, garantindo a generalidade que lhe foi dada (MACCORMICK, 2010, p.72).

\section{Argumentos de princípios gerais do Direito}

De igual modo, a utilização de um princípio (ou princípios) geral aplicável à emissão de uma disposição legislativa, demanda que a tarefa interpretativa observe a coerência com o princípio (ou princípios) adotado, levando em conta o grau de relevância do princípio, tanto em geral como na área do direito que diz respeito (MACCORMICK, 2010, p. 72).

\section{$\underline{\text { Argumento histórico }}$}

Se uma lei (ou um grupo de leis) tem sido interpretada em conformidade com o entendimento que se desenvolveu, historicamente, acerca do objeto e de sua finalidade ou tenha incorporado uma compreensão do conceito de correção, então a interpretação a casos concretos deve ser compatível com esse entendimento histórico sobre o objeto e finalidade e compreensão correta que lhe é precedente (MACCORMICK, 2010, p. 72).

MacCormick, para completar o contexto jurídico que fundamenta a importância de tais argumentos sistêmicos, chama a atenção para o ideal de coerência total, sob a perspectiva de que o sistema jurídico é um sistema dotado de integridade e que sua proposta interpretativa favorece o alcance desse ideal:

Nos dilemas interpretativos, recorrer à argumentação sistêmica mostra uma consideração especial para essa qualidade geral de coerência racional e inteligibilidade em direito. Envolve a imposição de um princípio superior de racionalidade na realidade institucional do direito. Como tal, ele adiciona um elemento que faltou de nossos dois argumentos substantivos como elementos de pura argumentação prática. $\mathrm{O}$ argumento de coerência é um complemento necessário à argumentação teleológica e à argumentação deontológica em qualquer contexto institucional no qual se aprecie a existência de uma boa razão para recorrer conjuntamente a uma pluralidade de normas, e não apenas a objetivos ou princípios isolados identificados como relevantes em cada momento (MACCORMICK, 2010, p. 73) (tradução nossa) $)^{7}$.

\footnotetext{
${ }^{7 " E n ~ l o s ~ d i l e m a s ~ i n t e r p r e t a t i v o s, ~ r e c u r r i r ~ a ~ l a ~ a r g u m e n t a c i o ́ n ~ s i s t e ́ m i c a ~ m u e s t r a ~ u n a ~ c o n s i d e r a c i o ́ n ~ e s p e c i a l ~ p o r ~ e s t a ~ c u a l i d a d ~ g e n e r a l ~}$ de coherencia racional e inteligibilidad en el derecho. Involucra la imposición de un principio superior de racionalidaden la realidad institucional del derecho. Como tal, añade un elemento que faltaba a nuestros dos argumentos sustantivos como elementos de la argumentación práctica pura. El argumento de coherencia es un suplemento necesario a la argumentación teleologica y a la argumentación deontológica en cualquier contexto institucional en el que se aprecie que existe una buena razón para recurrir conjuntamente a una pluralidad de normas, y no sólo a aislados objetivos o principios identificados como relevantes em cada momento" (MACCORMICK, 2010, p. 73).
} 


\section{ARGUMENTOS TELEOLÓGICOS-DEONTOLÓGICOS}

Argumentos de interpretação teleológicas referem-se ao fim ou finalidade atribuída a um dispositivo legal, o qual se presume ter sido promulgado por um legislador racional em um contexto histórico específico. Em termos negativos, expressa a situação indesejável que, supostamente, o legislador tentou remediar, em termos positivos, como um presumível bom estado de coisas atribuído como finalidade e objeto do ato de legislar, em que o telos ou objetivo é independente dos termos do texto promulgado, e, portanto, precisa ser interpretado para realizar o propósito (MACCORMICK, 2010, p. 74).

Assim, o argumento teleológico/deontológico é uma aplicação da argumentação prática, onde a pergunta sobre o objetivo do dispositivo legal leva em consideração o contexto histórico e sistêmico, permitindo diferenciar o questionamento de qual o melhor propósito a perseguir, o melhor princípio a aplicar, daquele que revela as verdadeiras perguntas de interpretação: "Que objetivo é plausível atribuir a este texto legal particular, ou qual princípio formula melhor o seu objetivo subjacente?” (MACCORMICK, 2010, p. 74) (tradução nossa).

\section{A DECISÃo ADEQUAdA COMO NORMA DOTADA DE COERENCIA E CONSISTENCIA}

Conforme expostos nas sessões precedentes, os requisitos para avaliar se uma decisão está corretamente fundamentada se conectam, ressaltando a ideia de coerência racional e inteligibilidade do direito. Mas a multiplicidade de categorias de argumentos interpretativos dá ensejo a situações em que o julgador se depara com uma interpretação diferente, a depender do argumento aplicado. É dizer, cada argumento pode gerar uma interpretação diferente e, até contraditória, da gerada por outro argumento possível. Mesmo que se trate de argumentos de mesma categoria, não há garantia de que os argumentos apontem a mesma direção (MACCORMICK, 2010, p. 74).

Havendo argumentos conflitantes, propõe o autor a aplicação da chamada regra de ouro ${ }^{9}$, segundo a

\footnotetext{
8"qué objetivo es plausible atribuir a este texto jurídico concreto, o qué principio formula mejor su objetivo subyacente?" (MACCORMICK, 2010, p. 74).

${ }^{9}$ MacCormick (2010, p.75) toma por referência a regra insculpida por Lord Blackburn, em Weger vs. Commissions Adamson (1874-1978). Em River Wear Commissioners v Adamson (HL 1877), Lord Blackburn a "regra de ouro" é assim exposta: "It is to be borne in mind that the office of the judge is not to legislate, but to declare the expressed intention of the legislature even if that expressed intention appeared to the court to be injudicious; and I believe that it is not disputed that what Lord Wensleydale used to call the Golden rule is right viz. that we are to take the whole statute together and construe it all together, giving the words their ordinary significance unless when so applied they produce an inconsistency or an absurdity or inconvenience so great as to convince the court that the intention could not have been to use them in their ordinary signification and to justify the court in putting on them some other significance which though less proper is one which the court thinks the words will bear" (River Wear
} 
qual os termos da norma devem ser, em regra, aplicados conforme seu sentido ordinário, de acordo com as convenções sintáticas e semânticas da língua, sem ampliações ou restrições, salvo se o sentido produzido se mostre injusto, contraditório, anômalo ou absurdo.

Mas, em verdade, a regra de ouro não é uma regra em si, devendo ser considerada como uma máxima de sabedoria prática interpretativa, que indica uma abordagem para lidar com os variados tipos de argumentos nos casos que se apresentam dificuldades interpretativas decorrentes de conflitos entre os argumentos relevantes (MACCORMICK, 2010, p. 76).

Afora isso, a escolha do julgador diante de uma multiplicidade de argumentos conflitantes deve sempre se guiar pela concepção de que a norma produzida na decisão faz parte do sistema jurídico, devendo fazer sentido, quando analisada como um todo. Nessa perspectiva, a coerência e a consistência são complementos distintos e necessários para a correta fundamentação de uma decisão.

O autor interpreta a consistência como sendo satisfeita pela não contradição lógica entre as diversas proposições. A coerência, por sua vez, ocorre quando o grupo de proposições, tomadas em seu conjunto, faz sentido como um todo. A ideia de coerência está ligada ao caráter valorativo do ordenamento jurídico, que confere compatibilidade entre duas ou mais regras, justificáveis em vista de um princípio comum (MARTINS; ROESLER; JESUS, 2011, p. 215).

MacCormick distingue ainda a coerência normativa e a coerência narrativa. As decisões judiciais devem sempre observar os dois aspectos. A coerência normativa caracteriza-se por ser sincrônica (relativa a norma vigente ao tempo da decisão) e a coerência narrativa por ser diacrônica (relativa aos fatos narrados no tempo). Ambas devem refletir um ideal de sistematicidade perseguido pela ordem jurídica. Ao fundamentar uma decisão, também os fatos devem ser narrados de forma lógica, é dizer, numa sequência inteligível de eventos que façam sentido como um todo, sendo essa a base de sustentação de conclusões, opiniões ou veredictos sobre fatos ocorridos (MARTINS; ROESLER; JESUS, 2011, p. 215/2016).

Apesar de conferir excessiva valorização à coerência, MacCormick não limita a qualidade das decisões a esse elemento, na medida em que propõe que ela esteja em sintonia com os princípios aceitos pela comunidade. Não qualquer princípio, mas aqueles que reflitam um ideal de uma vida satisfatória, de mútuo respeito e busca por igualdade de tratamento e universalização dos fundamentos da decisão, sendo certo que os princípios e valores acolhidos pelas comunidades devem transparecer nas decisões políticas e jurídicas que lhes afetam, por serem eles (princípios e valores) que asseguram a legitimidade da interpretação conferida à norma (MARTINS; ROESLER; JESUS, 2011, p. 219).

Commissioners v Adamson; HL 1877. In: swarb.co.uk, May the law be with you. Disponível em: <http://swarb.co.uk/river-wear- 
A argumentação jurídica deve ser orientada, portanto, por uma razão prática de construção e desenvolvimento constantes do ordenamento jurídico, em sua integridade, refletindo, em última instância, os fundamentos que norteiam o Estado Democrático de Direito. Quando se busca explicar e justificar a melhor aproximação da interpretação jurídica em casos problemáticos, é necessário refletir sobre os valores e princípios adequados às instituições sociais, aos estados e às comunidades internacionais e supranacionais que habitamos, sobre o significado do constitucionalismo, democracia, princípio da legalidade, separação de poderes, justiça procedimental, equidade, direitos humanos e integridade das instituições estatais. Não se pode, assim, restringir a argumentação jurídica a uma argumentação puramente interpretativa, haja vista que, para se formar uma visão sobre o direito, apesar de poder ser um conceito interpretativo, deve-se ir além da interpretação de seu conceito e dos textos jurídicos, aliando-se uma argumentação prática (MACCORMICK, 2010, p. 77).

\section{ANÁLISE DOS ARGUMENTOS INTERPRETATIVOS INVOCADOS NO RECEBIMENTO DA DENÚNCIA NOS AUTOS DE INQUÉRITO No 3.932/DF}

Sob a ótica da teoria argumentativa apresentada, a decisão objeto de análise (BRASIL, 2016) teve por ponto de partida a narrativa dos fatos e suas circunstâncias, de forma cadenciada, além de apontar as alegações de acusação e defesa e os indícios de prova até então produzidos, para então apresentar as razões de decidir na parte dispositiva ou voto.

O Inquérito 3.932, foi ajuizado em face de JAIR MESSIAS BOLSONARO, em razão das manifestações do parlamentar proferidas no dia 09/12/2014, no Congresso Nacional e, posteriormente, no dia 10/12/2014, em entrevista concedida ao jornal Zero Hora, servidor de base para o oferecimento da denúncia, por parte do Ministério Público Federal, imputando ao parlamentar a prática do crime definido no art. 286 do Código Penal (incitação ao crime).

Segundo consta, o parlamentar afirmou publicamente que não estupraria a Deputada Federal Maria do Rosário porque ela não merece, respondendo, sobre o motivo dessa afirmação, que "Não merece porque ela é muito ruim, porque ela é muito feia, não faz meu gênero, jamais a estupraria. Eu não sou estuprador, mas, se fosse, não iria estuprar, porque não merece".

Apresentado o relatório, a parte dispositiva do julgado tem início com a exposição do sistema jurídico de proteção da vida, integridade física e dignidade da mulher, no âmbito internacional, com destaque para a Convenção Interamericana para Prevenir, Punir e Erradicar a Violência contra a Mulher - "Convenção de Belém do Pará" (1994); a Convenção sobre a Eliminação de Todas as Formas de Discriminação contra a Mulher - 
"Carta Internacional dos Direitos da Mulher" (1979); além das conferências internacionais sobre a mulher realizadas pela $\mathrm{ONU}$, ressaltando que o Brasil se obrigou a proteger atos potencialmente violadores de direitos previstos na Constituição, destacando, em seguida, o entendimento jurisprudencial no sentido de que, em matéria de direitos humanos, a interpretação jurídica há de considerar, necessariamente, as regras e cláusulas do direito interno e do direito internacional.

O argumento histórico se destaca, na medida em que os tratados e convenções internacionais que tratam da violência sexual revelam a necessidade da decisão adotada conferir aos conceitos trabalhados a interpretação jurídica que mais se adéque ao objetivo de proteção contra esse tipo de crime. Nesse sentido, a experiência de desrespeito da dignidade humana, a exemplo da violência sexual contra a mulher, possui uma função desveladora, em que intuição adentra inicialmente na consciência dos afetados para, depois, ingressar nos textos jurídicos, articuladas na forma de conceitos (HABERMAS, 2011, p. 34).

A decisão destaca, também, que, em âmbito nacional, foi promulgada a Lei Maria da Penha $(11.340 / 2006)$ que trouxe um novo paradigma para a proteção da mulher, ao estabelecimento de pena mais grave o Feminicídio e normas, voltadas a coibir mortes, lesões e imposições de sofrimento físico e psicológico à mulher.

Vê-se que o acórdão analisado lança mão do argumento por analogia, de normas internacionais (Convenção Interamericana para Prevenir, Punir e Erradicar a Violência contra a Mulher, 1994; Convenção sobre a Eliminação de Todas as Formas de Discriminação contra a Mulher, 1979) e de norma interna específica de proteção contra a violência doméstica (Lei Maria da Penha), para justificar a necessidade de medidas judiciais coibitivas de discursos, ainda que genéricos, que, de alguma forma, exaltem a violência sexual contra a mulher.

Sobre o estupro, segue o acórdão esclarecendo a percepção social negativa sobre o papel da vítima e sobre a difusão dessa prática como "manifestação de violência e poder", conforme compreensão desenvolvida "a partir da tese de Susan Brownmiller", segundo a qual “a ameaça perene do estupro mantém todas as mulheres em situação de subordinação". Nesse cenário, o decisum aponta para a relevância do direito na "construção social das subjetividades", cabendo ao jurista levar em consideração, no caso concreto, "a discriminação e a violência que caracterizam as relações de gênero no país".

O acórdão leva em consideração que, no Brasil, a violência sexual contra a mulher é, numa visão patriarcal e machista, consequência (punição) da ocupação do espaço público reservado ao homem, o que caracteriza essa espécie de violência sexual como violência de gênero ${ }^{10}$. $O$ crime de estupro, previsto no art. 213 do

\footnotetext{
${ }^{10}$ Para Viveiro de Castro, "[... É de justiça responsabilizar em primeiro lugar a própria mulher, dominada pela ideia errônea, subversiva, de sua emancipação, ela faz tudo que de si depende para perder o respeito, a estima e a consideração dos homens. A antiga educação da mulher recatada e tímida, delicada sensitiva evitando os contatos ásperos e rudes da vida, foi desprezada como
} 
Código Penal, consiste em: "Constranger alguém mediante violência e grave ameaça, a ter conjunção carnal ou a praticar ou permitir que com ele se pratique outro ato libidinoso", mas, originalmente, se referia aos "costumes" da época, tanto que os crimes sexuais eram intitulados "Dos crimes contra os costumes" e somente admitiam a mulher como vítima. Com o advento da Lei 12.015/2009, passou a se referir à dignidade sexual, sem distinção de gênero. Essa alteração ultrapassa a questão semântica, refletindo a mudança do bem jurídico tutelado pelo Estado, que, no lugar da preservação da moral e dos bons costumes, se volta à dignidade da pessoa humana, ampliando a esfera de proteção da honra para a integridade física e psicológica da vítima, independente de seu gênero.

Sobre o tipo penal do art. 286 do Código Penal, a tese da defesa sustentou a atipicidade da conduta atribuída ao parlamentar, alegando que não houve incitação à prática do crime e que afirmações genéricas não são suficientes para o preenchimento das elementares típicas do art. 286 do Código Penal. Rechaçando essa tese, argumentou o Relator que a incitação ao crime se acha inserida no Título dos crimes contra a paz pública, portanto está ligada ao aspecto subjetivo da ordem pública, que seria o sentimento de paz e tranquilidade social.

Denota-se que a interpretação levou em consideração que o propósito do legislador, na tipificação da incitação ao crime, foi expressar uma situação indesejável de perturbação da ordem pública. O sentido do termo é alcançado por meio da significação sintática e semântica da palavra "incitar", aliada ao significado técnico conferido pela doutrina especializada. A incitação ao crime não importa, portanto, num ataque concreto ao bem jurídico protegido, mas se destina a proteger o valor desse bem jurídico do crime objeto de incitação. Assim sendo, no caso de incitação do crime de estupro, a conduta se apresenta quando o valor do bem jurídico protegido (liberdade sexual) for diminuído, o que, consequentemente, incitaria a sua prática.

Os argumentos linguísticos foram articulados quanto a expressão "merecer", a partir de seu significado ordinário, como sendo algo referente a premiação/mérito. Restou consignada a potencialidade da relativização do valor do bem jurídico protegido - a honra, a integridade psíquica e a liberdade sexual da mulher - gerar, ou reforçar, a ideia de que as mulheres, por suas qualidades físicas ou por outras razões, "mereceriam" ser vítimas de estupro $^{11}$, incentivando uma cultura de dominação da mulher, e potencializando a ideia de transferir para a

coisa anacrônica e ridícula; e temos hoje a mulher moderna, vivendo nas ruas, sabendo tudo, discutindo audaciosamente as mais escabrosas questões, sem refreio religioso, ávida e unicamente de luxo e sensações, vaidosa e fútil, presa fácil e muita vez até espontaneamente oferecida à conquista do homem" (Apud: CUNHA; FERNANDES, 2014).

${ }^{11}$ O Fórum Brasileiro de Segurança Pública divulgou pesquisa realizada pelo instituto Datafolha, em que 30\% dos entrevistados concordaram com a seguinte afirmação: "A mulher que usa roupas provocativas não pode reclamar se for estuprada". Significa dizer que, um em cada três brasileiros concorda que a mulher vítima de estupro é, de alguma forma, responsável pela violência sexual sofrida. O percentual foi o mesmo entre homens e mulheres. Esse índice aumenta entre idosos e adultos com mais de 35 anos e entre as pessoas com menor grau de escolaridade. $37 \%$ dos participantes também concordaram com a frase "Mulheres que se dão ao respeito não são estupradas”. O percentual foi maior entre os homens (42\%) em relação às mulheres (32\%). O resultado da pesquisa indica que muitas vezes as próprias mulheres ainda são consideradas responsáveis pela violência sexual, seja em razão de seu comportamento "inadequado" ou da maneira que se vestem ser considerada provocante. Foram entrevistadas 3.625 pessoas, 
própria vítima a culpa por ser alvo dessa espécie de crime.

Encontra-se, ainda, no voto do Relator, a concepção de Direito e de interpretação jurídica adotada pelo julgador, destacando que não se trata de juízo de subsunção do fato à norma positiva jurídica, mas de "momento supremo do direito em que ressaltam muito mais os valores do que fatos sociais", atentando para o cuidado que se deve ter com os valores sociais que norteiam, inconscientemente, os argumentos lançados pelo julgador, impedindo o desempenho de suas funções tendo em vista "o respeito, a dignidade e a justiça”.

Noutras palavras, a decisão, além dos argumentos interpretativos (linguístico, sistêmico e histórico), não deve olvidar dos argumentos práticos. Nessa perspectiva, o Relator do acórdão, com o intuito de demonstrar a potencialidade dos comentários proferidos pelo Denunciado, transcreveu em seu voto os comentários oriundos de redes sociais, nos quais os emissores expõem a adesão ou não à manifestação do Acusado, a partir da avaliação subjetiva da beleza da vítima, concluindo:

Nota-se que, ao menos em tese, a manifestação do Acusado tem o potencial de incitar outros homens a expor as mulheres à fragilidade e à violência, física, sexual, psicológica, inclusive novos crimes contra a honra da vítima e de mulheres em geral - porquanto praticado por um Parlamentar, que não pode desconhecer os tipos penais de lei oriunda da Casa Legislativa onde exerce seu munus público (Brasil, 2016).

A menção a existência de notícias de estupro coletivo reforça a preocupação do julgador com a vulnerabilidade das mulheres a esse tipo de crime. Além disso, enfatizou a campanha "\#eu não mereço ser estuprada", iniciada na internet em seguida à divulgação das declarações do Acusado, tomando o fato como uma ofensa grave contra as mulheres do país, na medida em que o vocábulo "merece" foi compreendido como insulto de gênero, que revela o desprezo à dignidade sexual da mulher.

O recebimento da denúncia foi precedido da análise da possibilidade de responsabilidade criminal do réu, tendo em vista que o mesmo, por ser Deputado Federal, goza de imunidade parlamentar material (art. 53 da Constituição Federal), que lhe assegura a liberdade absoluta de expressão, no exercício de suas funções. Tal imunidade foi afastada a partir do entendimento que se desenvolveu, historicamente, acerca do objeto e de sua finalidade. A imunidade parlamentar material é uma prerrogativa dos membros do Congresso Nacional, que lhes garante exercer a liberdade de opinião. Vê-se que não se trata de privilégio, pois se assim o fossem, as imunidades poderiam formar direitos subjetivos. É garantia da função e não privilégio pessoal. Os privilégios denotam interesse pessoal de seus beneficiários. Já as prerrogativas visam ao regular exercício de funções do Estado, se

com 16 anos ou mais, em 217 municípios, entre os dias $1^{\circ}$ e 5 de agosto de 2016. A margem de erro é de 2 pontos percentuais para mais ou para menos. O levantamento revelou ainda que $85 \%$ das mulheres entrevistadas têm medo de ser estupradas. Em 2014, foram registrados 47.646 estupros no Brasil, correspondendo a média de uma mulher estuprada a cada 11 minutos. Mas, estimativas apontam que apenas 10\% desse tipo de crime é registrado. Os dados revelam que, no Brasil, as pessoas associam a vitimização da mulher a uma conduta moral. (LIMA, Renato Sérgio de; BUENO, Samira. Percepção sobre violência sexual e 
afastando da ideia de mera satisfação de interesses particulares (HORTA, 2014).

A inviolabilidade abrange os discursos pronunciados, em sessões ou nas Comissões, os relatórios lidos ou publicados, e assim os votos proferidos pelos Deputados ou Senadores (HORTA, 2014). Esse é o critério adotado tradicionalmente pelo Supremo Tribunal Federal, qual seja, que as declarações proferidas por parlamentar dentro do Congresso Nacional seriam sempre protegidas pela imunidade parlamentar, ainda que as declarações não tivessem relação com o exercício do mandato, pelo qual gozam de liberdade de opinião ${ }^{12}$.

Nesse sentido, o voto condutor do acórdão também ressalta que as declarações prestadas pelo Deputado dentro do plenário até poderiam estar cobertas pela imunidade absoluta. Mas, no caso, embora no gabinete parlamentar, a ofensa ocorreu por meio de entrevista a jornal. Fora do Parlamento, a imunidade é relativa, é dizer, é necessário que a manifestação feita tenha relação com o exercício do seu mandato. Palavras e opiniões de cunho pessoal, sem relação com o debate democrático, sem vínculo com o exercício das funções parlamentares, não estão protegidos pela imunidade material.

É necessário que as suas declarações guardem relação com o desempenho da função legislativa ou tenham sido proferidas em razão dela. Ou seja, elas devem ter, ainda de forma mínima, um teor político, serem relativas a sobre fatos que estejam sendo debatidos pela sociedade ou sejam objeto de investigações; opiniões sobre temas que sejam de interesse de determinados setores da sociedade, do eleitorado, de organizações ou grupos representados no parlamento etc.

No caso concreto, ao receber a peça acusatória, o Supremo Tribunal Federal se pronunciou no sentido de que, as palavras assacadas por Bolsonaro, de que a Deputada Federal Maria do Rosário não merecia ser estuprada porque seria muito feia, não estavam vinculadas com o exercício do mandato. Os Ministros, por maioria, acolheram o entendimento do relator de que, o fato do parlamentar estar em seu gabinete, no momento

atendimento a mulheres vítimas nas instituiçoes policiais. \#ApolíciaPrecisaFalarSobreEstupro. Setembro, 2016. Disponível em: $<$ http://www.forumseguranca.org.br/storage/download/percepcao-violencia-mulheres-b.pdf $>$. Acesso em: 26 nov. 2016)

${ }^{12}$ Após o recebimento da Denúncia (Inq 3932), o STF dá sinais de mudança de interpretação à imunidade parlamentar material absoluta, passando a enfatizar o conteúdo das declarações (se relacionadas à atividade parlamentar) ao local de prolação da declaração (tribuna/recinto parlamentar): "Queixa-crime. Ação penal privada. Competência originária. Crimes contra a honra. Calúnia. Injúria. Difamação. 2. Art. 53 da Constituição Federal. Imunidade parlamentar material. A imunidade é absoluta quanto às manifestações proferidas no interior da respectiva casa legislativa. O parlamentar também é imune em relação a manifestações proferidas fora do recinto parlamentar, desde que ligadas ao exercício do mandato. Precedentes. Possível reinterpretação da imunidade material absoluta, tendo em vista a admissão de acusação contra parlamentar em razão de palavras proferidas no recinto da respectiva casa legislativa, mas supostamente dissociadas da atividade parlamentar - PET 5.243 e INQ 3.932, rel. min. Luiz Fux, julgados em 21.6.2016. Caso concreto em que, por qualquer ângulo que se interprete, as declarações estão abrangidas pela imunidade. Declarações proferidas pelo Deputado Federal querelado no Plenário da Câmara dos Deputados. Palavras proferidas por ocasião da prática de ato tipicamente parlamentar - voto acerca da autorização para processo contra a Presidente da República. Conteúdo ligado à atividade parlamentar. 3. Absolvição por atipicidade da conduta" (Pet 6156, Relator(a): Min. GILMAR MENDES, Segunda Turma, julgado em 30/08/2016, PROCESSO ELETRÔNICO DJe-207 DIVULG 27-09-2016 PUBLIC 28-09-2016). 
em que concedeu a entrevista, é de menor importância, porque as ofensas se tornaram públicas por meio da imprensa e da internet, quando a entrevista foi veiculada.

Dessa forma, as declarações prestadas em entrevista concedida ao Jornal Zero Hora, veículo de grande circulação, afasta o entendimento de que a imunidade material seria absoluta. E, como, no caso concreto não estavam relacionadas com a função parlamentar, não há que se falar em imunidade material do art. 53 da CF/88.

À luz da teoria argumentativa de MacCormirck, o recebimento da denúncia de incitação ao crime analisada lançou mão das diversas categorias ou tipos de argumentos interpretativos relevantes para aferir a adequação da decisão, de forma coerente e consistente com os fundamentos do Estado brasileiro:

\begin{tabular}{|c|c|}
\hline $\begin{array}{c}\text { Argumentos } \\
\text { linguísticos }\end{array}$ & 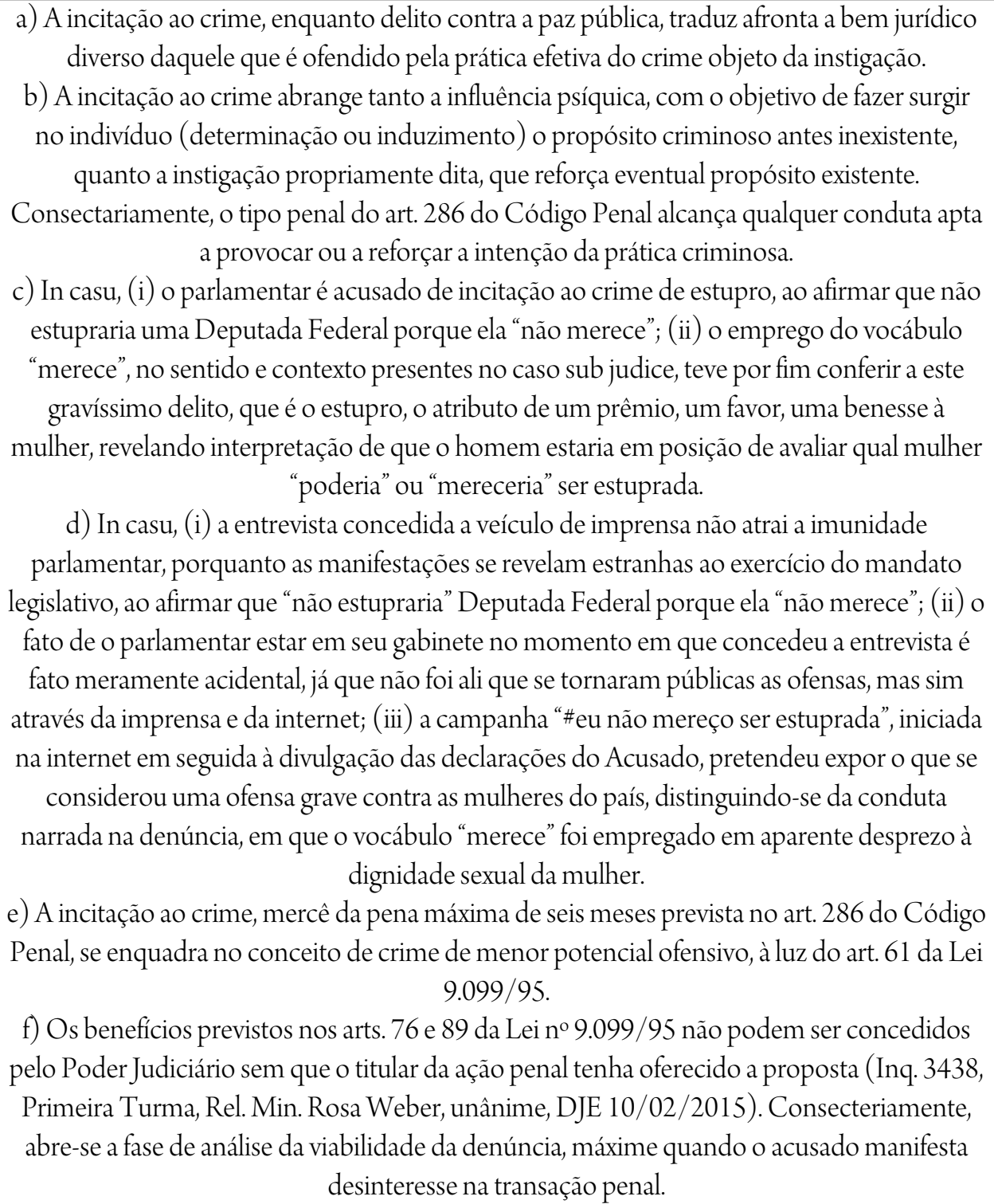 \\
\hline $\begin{array}{l}\text { Argumentos } \\
\text { sistêmicos }\end{array}$ & $\begin{array}{l}\text { a) Os Tratados de proteção à vida, à integridade física e à dignidade da mulher, com } \\
\text { destaque para a Convenção Interamericana para Prevenir, Punir e Erradicar a Violência } \\
\text { contra a Mulher - "Convenção de Belém do Pará" (1994); a Convenção sobre a Eliminação } \\
\text { de Todas as Formas de Discriminação contra a Mulher - "Carta Internacional dos Direitos }\end{array}$ \\
\hline
\end{tabular}




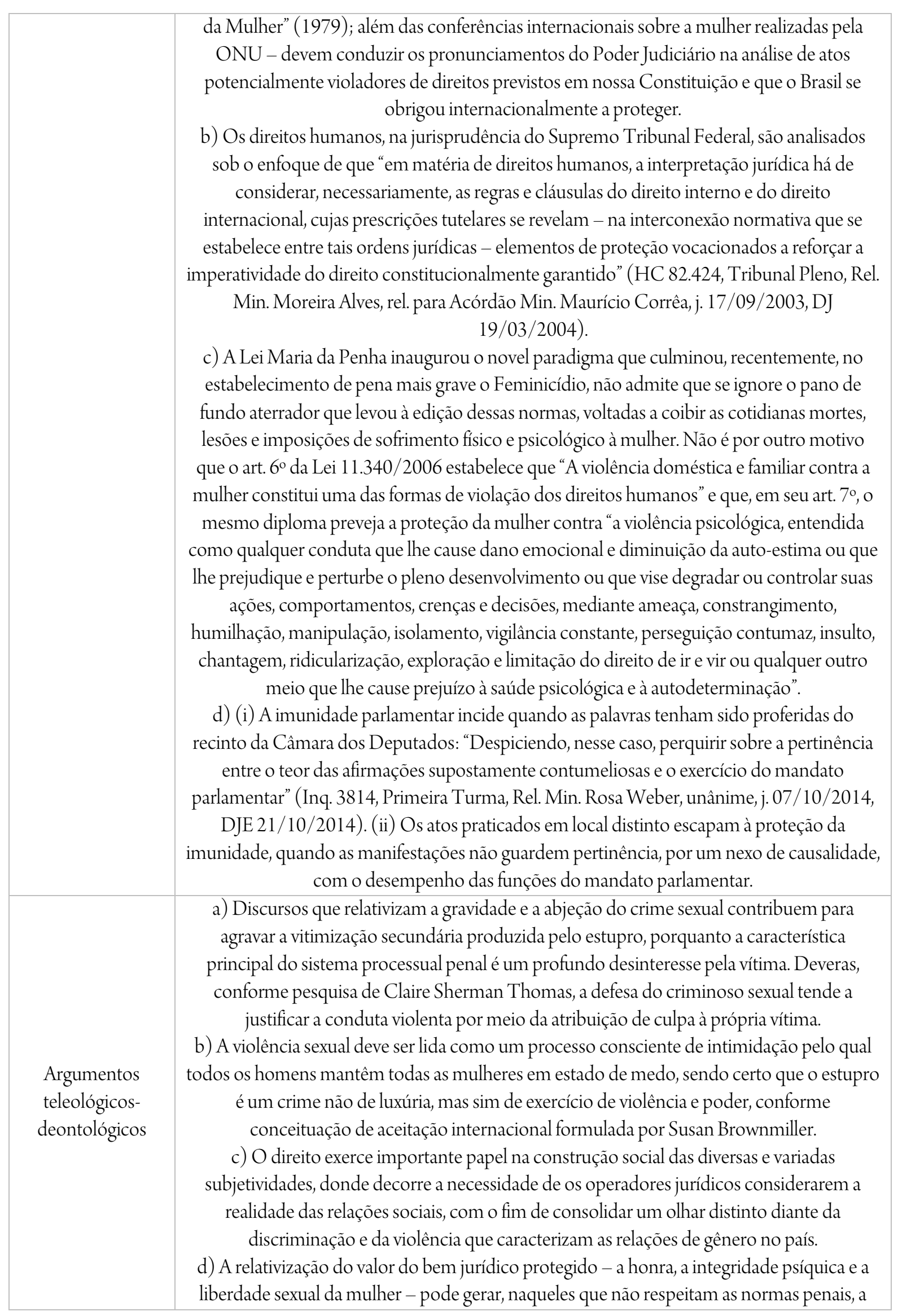


tendência a considerar mulheres que, por seus dotes físicos ou por outras razões, aos olhos de potenciais criminosos, "mereceriam" ser vítimas de estupro.

e) O desprezo demonstrado pelo bem jurídico protegido (dignidade sexual) reforça e incentiva a perpetuação dos traços de uma cultura que ainda subjuga a mulher, com potencial de instigar variados grupos a lançarem sobre a própria vítima a culpa por ser alvo de criminosos sexuais, deixando, a depender da situação, de reprovar a violação sexual, como seria exigível mercê da expectativa normativa.

f) As recentes notícias de estupros coletivos reforçam a necessidade de preocupação com discursos que intensifiquem a vulnerabilidade das mulheres.

g) (i) A incitação ao crime, por consubstanciar crime formal, de perigo abstrato, independe da produção de resultado naturalístico. (ii) A idoneidade da incitação para provocar a prática de crimes de estupro e outras violências, físicas ou psíquicas, contra as mulheres, é matéria a ser analisada no curso da ação penal. (iii) As declarações narradas na denúncia revelam, em tese, o potencial de reforçar eventual propósito existente em parte daqueles que ouviram ou leram as declarações, no sentido da prática de violência física e psíquica contra a mulher, inclusive novos crimes contra a honra de mulheres em geral. (iv) Conclusão contrária significaria tolerar a reprodução do discurso narrado na inicial e, consequentemente, fragilizar a proteção das mulheres perante o ordenamento jurídico, ampliando sua vitimização.

\section{CONCLUSÃO}

A denúncia (Inquérito 3.932/DF) recebida pelo Supremo Tribunal Federal em desfavor do Deputado Federal Jair Bolsonaro (PSC-RJ), pela prática do crime de incitação ao crime de estupro se mostrou complexa, na medida em que o tradicional juízo de subsunção das declarações prestadas ao art. 286 do Código Penal não se mostrou suficiente para a aplicação da norma.

A decisão teve que se valer de argumentos interpretativos de variadas categorias, que fossem capazes de legitimá-la, especialmente quanto à observância aos valores e princípios que envolvem a questão do combate à violência contra a mulher e sua vitimização e, ainda, considerando, em contraponto, a garantia constitucional da imunidade parlamentar.

À luz da teoria da argumentação jurídica de Neil MacCormick, observou-se que a multiplicidade de argumentos de interpretação mantiveram a coerência e a consistência exigidas para manutenção da integridade do sistema jurídico.

Numa fase de juízo superficial, em que se discutia a admissibilidade da denúncia contra o Deputado Federal por declarações que, ainda que de forma genérica, revelam um discurso de violência de gênero, foram apresentadas argumentações de ordem jurídica e de ordem prática.

Nessa linha de raciocínio, a tese do Relator pautou-se nos princípios de proteção da vida, integridade física e dignidade da mulher, asseguradas no âmbito internacional pelos tratados e convenções que o Brasil 
assinou, sendo essas normas consideradas como orientadoras da tarefa interpretativa para alcançar a decisão mais adequada, por se tratar de matéria de direitos humanos. Além disso, os argumentos enfrentaram o contexto histórico e social envolvendo a violência contra a mulher no Brasil e a necessidade de promover sua proteção contra discursos sexistas, que reforçam um comportamento negativo, perturbador da paz social.

A decisão se orienta por um conceito de Direito condizente com o Estado Democrático, em que as minorias são alvo de proteção especial e demandam a adoção, por parte do Estado, de medidas que desestimulem atos que atentem à dignidade humana e, no caso em tela, a valores consagrados de não discriminação, igualdade de gênero e combate a violência sexual, os quais se obrigou a promover. O recebimento da denúncia deu ênfase ao contexto valorativo que estabelece os parâmetros sociais do exercício do direito fundamental à liberdade sexual, protegida de ataques violentos ou intimidatórios, mediante o reconhecimento da efetiva proteção jurídica que merece. Restou, assim, juridicamente evidenciada a correta fundamentação da decisão, tendo em vista a coerência e a consistência dos argumentos utilizados nessa fase processual, em que a instauração da ação penal representa mecanismo de proteção da sociedade contra ações que vilipendiam seus fundamentos.

\section{ANALYSIS OF THE DECISION TO RECEIVE THE COMPLAINT OF THE INCIDENT TO THE CRIME OF RAPE - INQUIRY 3,932 / DF - BASED ON THE ARGUMENTATIVE THEORY OF NEIL MACCORMICK}

\section{Resumo}

This paper analyzes the receipt of the complaint (Inquiry 3,932 / DF) offered by the Federal Public Ministry in favor of Federal Deputy Jair Bolsonaro (PSC-RJ), for the alleged practice of crime of incitement to crime, declaring that Federal Deputy Maria do Rosário (PT-RS) "does not deserve to be raped because it's very bad, very ugly, it's not my kind," adding that if he was a rapist, "he would not rape her because she does not deserve it." The theme had great repercussion in the Brazilian social context. Despite the social outcry, the issue is complex from the legal point of view, with a view to dealing with parliamentary immunity, on the one hand, and the sexual dignity of women, on the other, which denotes the importance of the legal debate. It is therefore sought to know whether the receipt of the complaint, in this case, is properly justified, from a legal point of view. The deductive method is used to categorize, based on a descriptive-analytical analysis of Neil MacCormick's theory of legal argument, the arguments used as grounds for the decision and to evaluate whether this decision expresses coherent and consistent arguments, in order to gauge the correction or not of its reasoning. As a result, it is concluded that the decision to receive the complaint for incitement to rape, in the case presented, is adequately grounded, using both legal and practical interpretative arguments that maintain narrative and normative coherence and consistency argumentative.

Keywords: Legal argument; Coherence; Consistency. 


\section{REFERENCIAS}

BRASIL. Supremo Tribunal Federal. Recebimento da denúncia. Ata no 131/2016. Autor: Ministério Público Federal. Réu: Jair Messias Bolsonaro. Relator: Ministro Luiz Fux. Brasília, DF, 21 de julho de 2016. Diário da Justiça Eletrônico. Brasília, 09 set. 2016.

CUNHA FILHO, Francisco Humberto; FERNANDES, Leonísia Moura. Violência sexual e culpabilização da vítima: sociedade patriarcal e seus reflexos no ordenamento jurídico brasileiro. Direitos, gênero e movimentos sociais II. XXIII Congresso Nacional do CONPEDI: A humanização do direito e a horizontalização da justiça no século XXI. Universidade Federal da Paraíba. João Pessoa/PB. 05-08 nov. 2014. Disponível em: <http://publicadireito.com.br/artigos/?cod=47f5d6b9ad18d160>. Acesso em: 27 nov. 2016.

DEL MAR, Maksmilian. Neil MacCormick. disponível em: <http://www.law.qmul.ac.uk/MacCormick/about/index.html>. Acesso em: 22 nov. 2016.

HABERMAS, Jürgen. Um ensaio sobre a Constituição da Europa. Lisboa: Edições 70, 201 1, p. $27-57$.

HORTA, Raul Machado. Imunidades parlamentares. In: CLEVE, Clemerson Merlin; BARROSO, Luís Roberto (Org.). Doutrinas Essenciais de Direito Constitucional. vol. IV. São Paulo: RT, 2011.p. 353-386.

LOPES, Ana Maria D Ávila; BENÍCIO, Márcio. Análise da decisão judicial sobre a "briga de galos" (Adin n. 1856/2011) a partir da teoria argumentativa de MacCormick. Revista Brasileira de Direito Animal, v. 10, n. 20. 2015. p. 37-58. Disponível em: <http://www.portalseer.ufba.br/index.php/RBDA/article/view/15296/10474>. Acesso em: 26 nov. 2016.

MACCORMICK, Neil. Argumentação jurídica e teoria do direito. São Paulo: Martins Fontes, 2006.

Argumentación e interpretación en el derecho. Doxa: Cuadernos de filosofia del derecho, 33, p. 65-78. 2010. Disponível em: <https://rua.ua.es/dspace/bitstream/10045/32593/1/Doxa_33_04.pdf >. Acesso em: 24 nov. 2016.

MARTINS, Argemiro Cardoso Moreira; Roesler, Claudia Rosane; JESUS, Ricardo Antônio Rezende de. A noção de coerência na teoria da argumentação jurídica de Neil MacCormick: caracaterização, limitações, possibilidades. Revista Novos Estudos Jurídicos, v 16, n 2, mai./ago. 2011. Disponível em: <http://www6.univali.br/seer/index.php/nej/article/view/3281/2064>. Acesso em: 22 nov. 2016.

Trabalho enviado em 18 de julho de 2017.

Aceito em 12 de dezembro de 2017. 